\title{
ANTIOXIDANT AND ANTIAPOPTIC EFFECTS OF COMBINED SIDR HONEY AND NIGELLA SATIVA OIL AGAINST PARACETAMOL-INDUCED HEPATO- NEPHROTOXICITY IN RATS
}

\author{
Mohamed Abdelmohsen Abdallah ${ }^{1}$, Mohamed Ali Zayed ${ }^{1}$ and Mohamed Elsayed Kelany ${ }^{2 *}$ \\ ${ }^{1}$ Physiology Department, Faculty of Medicine, Menoufeya University, Egypt. \\ ${ }^{2}$ Clinical Pharmacology Department, Faculty of Medicine, Zagazig University, Egypt
}

\begin{abstract}
Background: Acetaminophen (Paracetamol; PCM), commonly utilized as analgesic and antipyretic drug in many painful and febrile disorders, has been found to induce liver and renal disorders in both animals and humans. Its administration in a high dose causes hepatic and renal toxicities and results in hepato-renal cell deaths by activating multiple stress pathways. Objective: This study aimed to investigate and compare effects of Sidr honey (SH), Nigella sativa oil (NS) and their combination on the paracetamol (PCM)-induced hepato-renal toxicities in rats.

Methods: Forty male adult albino rats were divided into five groups and treated for 4 weeks ( $\mathrm{n}=8$ each): (1) the control group; receiving distilled water orally, (2) PCM-treated; receiving single high dose PCM (SHDP) of $1 \mathrm{~g} / \mathrm{kg}$ once orally, (3) NS- and PCM-treated (NS/P); receiving NS in the dose of $2 \mathrm{ml} / \mathrm{kg} / \mathrm{day}$ orally, and at the end of NS-treatment, the same single PCM dose is given, (4) SH- and PCM-treated (H/P); receiving SH in the dose of $1 \mathrm{~g} / \mathrm{kg} / \mathrm{day}$, and at the end of SH-treatment, the same PCM dose is given, (5) SH-, NS- \& PCM-treated (H\&NS/P) group; receiving SH and NS orally in the same doses, and at the end of treatments, the same PCM dose is given. Serum alanine transaminase (ALT), aspartate transaminase (AST), blood urea nitrogen (BUN), creatinine, total antioxidative capacity (TAC) and Fas ligand (Fas L), and liver tissue TAC were measured after sacrificing the rats at the end of experiment.

Results: Compared to control group, the SHDP-treated rats developed significant increases in serum ALT, AST, BUN, Creatinine and Fas 1, and decreases in serum and liver tissue TAC. SH, NS or more effectively the combined H/NS/P treatments produced significant decreases in serum ALT, AST, BUN, Creatinine and Fas 1, and increases in serum and liver tissue TAC when compared with SHDP-treated rats.

Conclusion: These findings suggested that oral combined SH and NS administration is more protective against PCM-induced hepato-renal toxicity in rats than using each of them alone. The collective data demonstrated that SH and NS have considerable ability to protect against oxidation, apoptosis, and other harmful effects of PCM in rats.
\end{abstract}

Keywords: Sidr honey, Nigella sativa, Paracetamol, Apoptosis, Oxidation.

Corresponding author: Mohamed Elsayed Kelany

Mobile: 00966501600435 KSA,

E.mail: drmkelany@hotmail.com

\section{INTRODUCTION}

D rug-induced hepatic injury is the commonest cause of acute hepatic failure $^{[1]}$. The direct toxic injury is dosedependent and predictable and can be experimentally-reproducible. The idiosyncratic damage is supported by the innate and the adaptive immune system. Unfortunately, druginduced liver and kidney injuries are significant and still unresolved clinical problem. Paracetamol (PCM)-induced toxicity is a common cause of acute hepatic and renal failure. It is predominantly metabolized through conjugation with sulfate and glucuronide, but a small amount is degraded by CYP2E1 to the highly reactive (toxic) metabolite $\quad \mathrm{N}$-acetyl-p-benzoquinoneimide

\section{Received: November 2015 \\ Accepted: January 2016}

$(\mathrm{NAPQI})^{[2,3]}$. Then, this toxic metabolite NAPQI is detoxified by binding with glutathione (GSH). If an extra amount of paracetamol reaches the liver, the liver conjugation capacity is overwhelmed and the remaining unbound NAPQI covalently binds to cellular and mitochondrial proteins, leading to cell death $^{[14]}$.

Al-Jabri stated that honey is a natural product which is widely used for its therapeutic effects [5]. It has been reported that honey contains about 200 compounds. Chinese, ancient Egyptians, Assyrians, Greeks and Romans used honey for wound healing and treatment of intestinal diseases. Also, all Muslims believed that Honey is a curative agent from nearly all diseases according to what confirmed in Tibb- 
e-Nabwi (Prophetic Medicine). Since few decades, honey was exposed, by several researchers, to laboratory and clinical investigations. Sidr honey is one of the most distinctive honeys. It is known as a veritable cure-all that can be used to eliminate a variety of ailments. This honey is made by bees that have fed solely on Sidr tree nectar. It has long been used as part of folk medicine in Hadramout region ${ }^{[6]}$.

Nigella sativa (N. sativa), known as black seed, is a used medicinal plant throughout the world. It is cultivated worldwide in many countries like Middle East region, South Europe, India and Pakistan ${ }^{[7]}$. Seeds and its oil have a prolonged folklore usage in different systems of medicines and food, and have been used for centuries in the treatment of various ailments [8]. It is considered, among Muslims, as one of the greatest forms of healing medicine. In the shadow of Ahmad et al. ${ }^{[9]}$, it was mentioned that black seed is used as the remedy for all diseases except death in one of the Prophetic hadith.

Aim of the work: The current work was aimed to investigate and compare effects of Sidr honey (SH), Nigella sativa oil (NS) and their combined use on the paracetamol (PCM) induced hepato-nephrotoxicity in rats.

\section{MATERIALS AND METHODS}

1. Drugs and chemicals: Paracetamol (PCM) (pure drug powder from Sigma-Aldrich Chemie, CAS-No. 103-90-2, UK). Pure Sidr honey (SH) was purchased from an exclusive honey shop in Saudi Arabia (obtained from Mountains of Hadramaut, Yemen) and stored at laboratory room temperature. Nigella sativa (NS) oil (a product of Iman International, UK) purchased from exclusive herbal shops.

2. Animals: Forty adult male Sprague-Dawley rats, weighing 200-250 grams each, were obtained from the experimental animal house of the Faculty of Medicine, Zagazig University, Egypt. The experiments were performed according to the guidelines of the Institutional Animal Care of the Zagazig Faculty of Medicine. The animals bred in the laboratory animal house in the Menoufeya Faculty of Medicine, Egypt, and in fully ventilated cages and in a temperature-controlled environment at $22 \pm 2^{\circ} \mathrm{C}$, in a $12 / 12$ hour lighting cycle, and fed on the laboratory chow diet.
3. The experimental design and animal groups: The rats were randomly divided into five groups of 8 animals each, as follows:

i. Normal control group: The rats received distilled water in the dose of $1 \mathrm{~mL} / \mathrm{kg}$ body weight/day orally by gavage for 4 weeks.

ii. Single high dose PCM-treated (SHDP) group: The rats received PCM orally by gavage (given in $0.2 \%$ gum tragacanth) [10] in the dose of $1 \mathrm{~g} / \mathrm{kg}$ once ${ }^{[11]}$.

iii. NS and PCM-treated (NS/P) group: The rats received NS oil in the dose of 2 $\mathrm{mL} / \mathrm{kg} /$ day ${ }^{[12]}$ for 4 weeks, and at the end of this NS-treatment duration, they received the same above dose of PCM.

iv. SH- and PCM-treated (H/P) group: The rats received $\mathrm{SH}$ (dissolved in distilled water) in the dose of $1 \mathrm{~g} / \mathrm{kg} /$ day ${ }^{[6]}$ for 4 weeks, and at the end of this SH-treatment, they received the above dose of PCM.

v. SH-, NS- \& PCM-treated (H\&NS/P) group: The rats received orally $\mathrm{SH}$ and NS in the same above doses for 4 weeks, and at the end of the duration of treatments, they received the above dose of PCM.

4. Experimental procedures: The duration of SH and/or NS treatment was four weeks. The drugs were administered orally with an intragastric tube (using a Portex 4FG cannula, Portex Ltd., Hythe, UK). At the end of the experiment period (4 weeks), the rats underwent the following procedures:

i. Collection of blood samples and separation of serum: After finishing the experiment, the rats were fasted overnight and then held in a glass chamber to be anesthetized with diethyl ether. The venous blood samples were collected by heparinized microcapillary tubes from the retro-orbital plexus ( 24 hours after the last drugs administration). The samples were incubated at $37^{\circ} \mathrm{C}$ until blood clotted and then centrifuged (5000 g, $10 \mathrm{~min}$ ) for separation of serum which was stored at $20^{\circ} \mathrm{C}$ till used for biochemical assays as described below.

ii. Tissue sampling: After collection of blood samples, rats were then sacrificed and their livers were excised, weighed and rapidly washed in cold normal saline and then kept in ice-cold isotonic potassium chloride solution $(1.15 \% \mathrm{KCl} \mathrm{w} / \mathrm{v})$ containing $0.1 \mathrm{mM}$ EDTA. The livers were then divided into 5 volumes of 
$50 \mathrm{mM}$ phosphate buffer $(\mathrm{pH}=7.4)$ and homogenized by a homogenizer fitted with a Teflon pestle. The homogenate was then centrifuged for $10 \mathrm{~min}$ at $3000 \mathrm{~g}$, the lipid layer was removed and the resulting supernatant was further centrifuged for $60 \mathrm{~min}$ at $15,000 \mathrm{~g}$ at $4^{\circ} \mathrm{C}$. The supernatant was stored at $-80^{\circ} \mathrm{C}$ till use $^{[13]}$.

iii. Biochemical assays: The serum were used to measure aspartate transaminase (AST), alanine transaminase (ALT), blood urea nitrogen (BUN), creatinine, total antioxidative capacity (TAC) and Fas ligand (Fas L). Also, the TAC in liver homogenate was investigated. The determination of the values of the investigated parameters was achieved with an automated analyzer (Hitachi, Japan) and commercial kits (Technichon, Germany) ${ }^{[14]}$.

iv. FasL assay: The protein levels of FasL in the serum were measured by dot blot assay. Serum samples $\left(\begin{array}{lll}1 & \mu l\end{array}\right)$ were put on nitrocellulose (NC) paper and were blocked using the blocking buffer [5\% non-fatty milk in TBST (a mixture of Tris-Buffered Saline and Tween 20) (10 mm Tris- $\mathrm{HCl} \mathrm{pH} 8.0,0.15 \mathrm{~mm}$ $\mathrm{NaCl}, 0.05 \%$ Tween 20] at room temperature for 1 hour. The NC paper was then incubated with primary antibody (FasL) for 1 hour at room temperature. After 3 washes in the TBST buffer, the NC paper was transferred to a secondary antibody (anti-rabbit IgG alkaline phosphatase conjugate) for $1 \mathrm{~h}$ at room temperature. After 3 washes in phosphatebuffered saline (PBS), the NC paper was developed with an alkaline phosphatase substrate (Sigma) for $10 \mathrm{~min}$ in the dark. Several concentrations of rat recombinant FasL as described above were used as standards. The target dots were analyzed and quantified densitometrically using a GS-700 Imaging Densitometer (BioRad). The experiments were repeated more than twice ${ }^{[15]}$.

v. The total antioxidant capacity (TAC) assay in the serum and tissue samples was assayed by commercially available kits (Randox labs, Grumlin, UK). The assay principle was based on the ability of antioxidants to quench the absorbance of the radical cation that is formed by the reaction of a chromogen with the peroxide and $\mathrm{H}_{2} \mathrm{O}_{2}{ }^{[16]}$.

5. Statistical analysis: The recorded parameters were expressed as means and standard error of means (mean \pm SEM) for all groups and statistically analyzed using SPSS (version 16) software, for the one-way analysis of variance (one-way ANOVA) followed by Post Hoc and least significant difference (LSD) tests. The level of acceptance for statistical significance was considered to be $\mathrm{P}<0.05$.

\section{RESULTS}

1. The effects of SHDP, NS/P, H/P and H\&NS/P treatments on the serum AST and ALT in rats (Table 1 and Figure 1): Single high oral PCM dose increased significantly $(P$ $<0.001)$ the serum ALT and AST in SHDPtreated group when compared to control group. $\mathrm{NS}, \mathrm{H}$, or combined H/NS treatments, when administered before PCM, decreased significantly $(P<0.001)$ the PCM-induced elevations in the serum ALT and AST in the NS/P-treated, H/P-treated and H\&NS/P-treated rats when compared to SHDP-treated rats. While, the combined H/NS treatment more effectively decreased these liver enzymes to nearly the control ranges.

Table 1: The effects of SHDP, NS/P, H/P and H\&NS/P treatments orally for 4 weeks on the serum AST (s.AST) and ALT (s.ALT) in rats

\begin{tabular}{|c|c|c|}
\hline Animal group & s.AST (U/L) & s.ALT (U/L) \\
\hline Control group & $44.63 \pm 0.26$ & $39 \pm 0.46$ \\
\hline SHDP-treated group & $94.38 \pm 1.28 \#$ & $61.38 \pm 0.38 \#$ \\
\hline NS/P-treated group & $81 \pm 0.46 \# \$$ & $57.25 \pm 0.88 \# \$$ \\
\hline H/P-treated group & $55.13 \pm 0.4 \# \$$ & $45.5 \pm 0.93 \# \$$ \\
\hline H\&NS/P-treated group & $45.25 \pm 0.37 \$$ & $39.75 \pm 0.49 \$$ \\
\hline
\end{tabular}




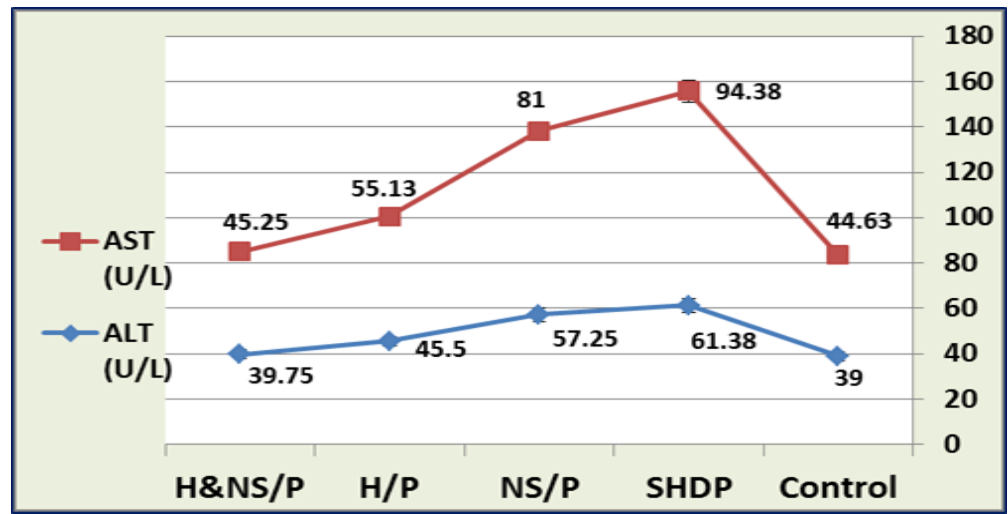

Figure 1: The effects of SHDP, NS/P, H/P and H\&NS/P treatments orally for 4 weeks on the serum AST and ALT in rats

2. The effects of SHDP, NS/P, H/P and H\&NS/P treatments on the serum BUN and creatinine in rats (Table 2 and Figures $2 \& 3$ ): Single high oral PCM dose increased significantly $(P<0.001)$ the serum BUN and creatinine in the SHDP-treated rats when compared to control group. NS, H, or combined H/NS treatments, when administered prior to
PCM, decreased significantly $(P<0.001)$ the $\mathrm{PCM}$-induced elevations in these parameters in the NS/P-treated, H/P-treated and H\&NS/Ptreated rats when compared to SHDP-treated rats. Furthermore, the combined H/NS treatment resulted in more effective decrements in these parameters to be nearly equal to the control ranges.

Table 2: The effects of SHDP, NS/P, H/P and H\&NS/P treatments orally for 4 weeks on the serum BUN and creatinine in rats

\begin{tabular}{lcc}
\hline \multicolumn{1}{c}{ Animal group } & s.BUN (mg/dl) & s.Creatinine (mg/d) \\
Control group & $18.36 \pm 0.57$ & $0.64 \pm 0.018$ \\
SHDP-treated group & $42.13 \pm 0.93 \#$ & $1.12 \pm 0.043 \#$ \\
NS/P-treated group & $34.75 \pm 0.59 \# \$$ & $0.79 \pm 0.016 \# \$$ \\
H/P-treated group & $27.38 \pm 0.42 \# \$$ & $0.71 \pm 0.009 \# \$$ \\
H\&NS/P-treated group & $19.38 \pm 0.41 \$$ & $0.65 \pm 0.006 \$$ \\
\hline
\end{tabular}

- $\quad$ Values are expressed as mean \pm SEM.

\#: Significant in comparison to control group.

\$: Significant in comparison to SHDP-treated group.

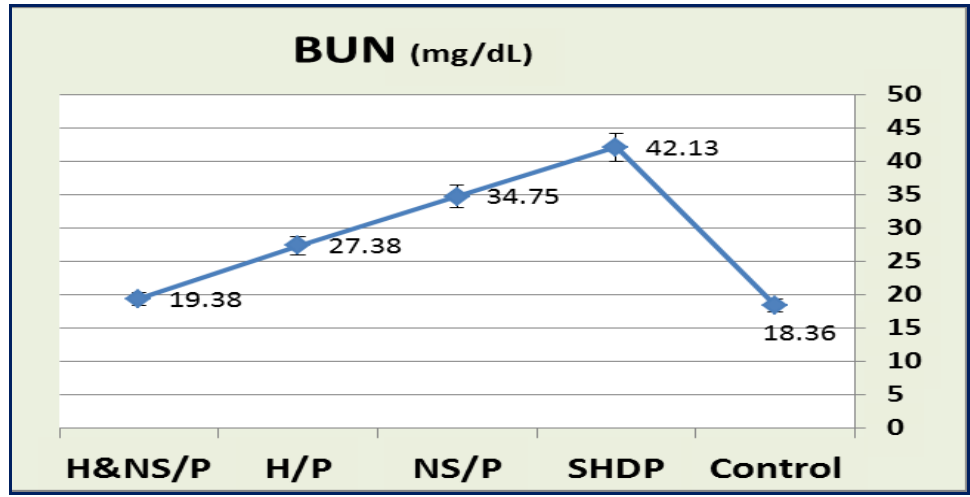

Figure 2: The effects of SHDP, NS/P, H/P and H\&NS/P treatments orally for 4 weeks on the serum BUN in rats 


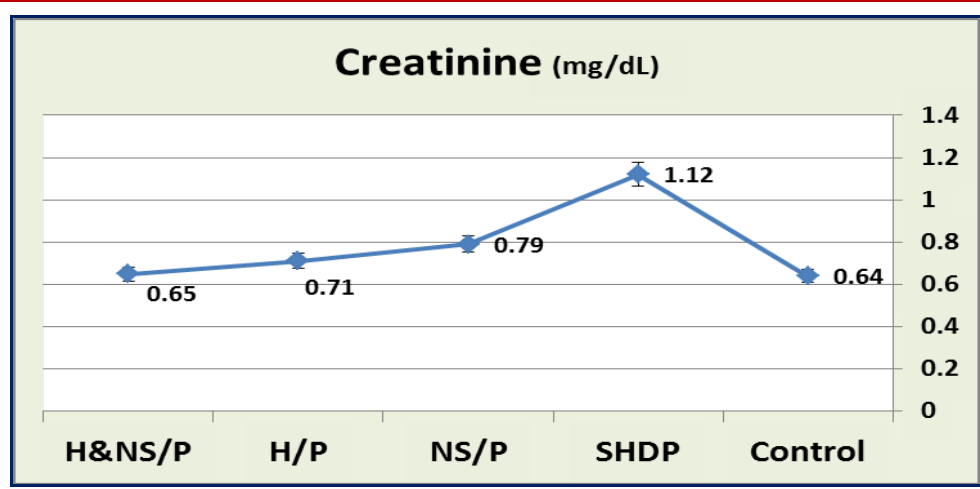

Figure 3: The effects of SHDP, NS/P, H/P and H\&NS/P treatments orally for 4 weeks on serum creatinine in rats

3. The effects of SHDP, NS/P, H/P and $H \& N S / P$ treatments on the serum TAC and tissue TAC in rats (Table 3 and Figures 4 \& 5): Single high oral PCM dose decreased significantly $(P<0.001)$ the serum TAC and tissue TAC in SHDP-treated group when compared to control group. NS, H, or combined H/NS treatments when administered before
PCM, increased significantly $(P<0.001)$ the $\mathrm{PCM}$-induced decreases in these parameters in the NS/P-treated, H/P-treated and H\&NS/Ptreated rats when compared to the SHDPtreated rats. In addition, the combined $\mathrm{H} / \mathrm{NS}$ treatment more effectively decreased the serum TAC and liver tissue TAC to be nearly equal to the control ranges.

Table 3: The effects of SHDP, NS/P, H/P and H\&NS/P treatments orally for 4 weeks on the serum and tissue TAC in rats

\begin{tabular}{lcc}
\hline \multicolumn{1}{c}{ Animal group } & S.TAC $(\boldsymbol{\mu m o l} / \mathbf{L})$ & t.TAC $(\mathbf{n m o l} / \mathbf{m g})$ \\
Control group & $2.12 \pm 0.022$ & $0.48 \pm 0.005$ \\
SHDP-treated group & $1.4 \pm 0.005 \#$ & $0.19 \pm 0.004 \#$ \\
NS/P-treated group & $1.6 \pm 0.006 \# \$$ & $0.4 \pm 0.004 \# \$$ \\
H/P-treated group & $1.82 \pm 0.005 \# \$$ & $0.46 \pm 0.003 \# \$$ \\
H\&NS/P-treated group & $2.03 \pm 0.02 \# \$$ & $0.48 \pm 0.004 \$$ \\
\hline
\end{tabular}

- $\quad$ Values are expressed as mean \pm SEM.

\#: Significant in comparison to control group.

\$: Significant in comparison to SHDP-treated group.

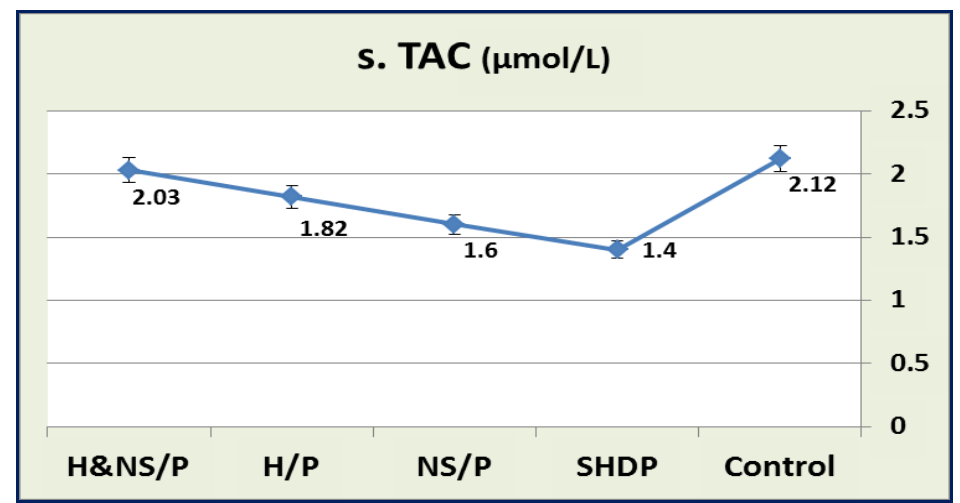

Figure 4: The effects of SHDP, NS/P, H/P and H\&NS/P treatments orally for 4 weeks on the serum TAC in rats 


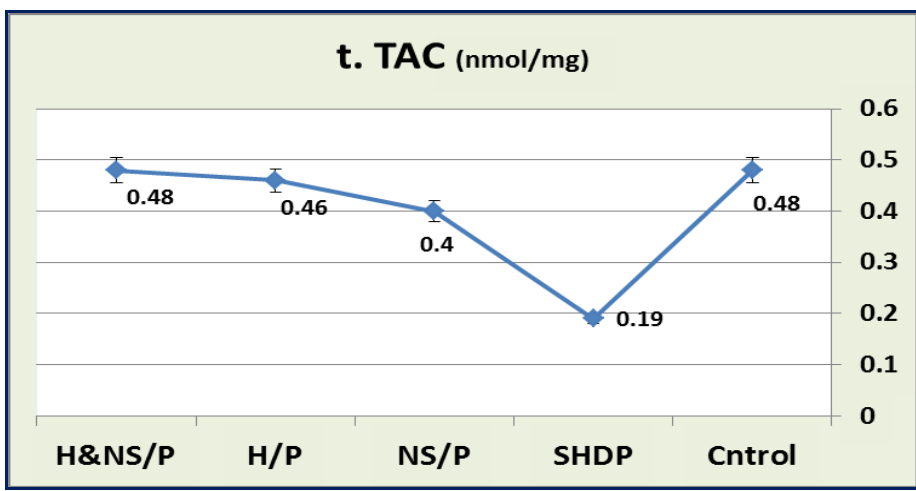

Figure 5: The effects of SHDP, NS/P, H/P and H\&NS/P treatments orally for 4 weeks on tissue $\mathrm{TAC}$ in rats

4. The effects of SHDP, NS/P, H/P and $H \& N S / P$ treatments on the serum FasL in rats (Table 4 and Figure 6): Single high oral PCM dose increased significantly $(P<0.001)$ the serum FasL in SHDP-treated group when compared to control group. NS, H, or combined $\mathrm{H} / \mathrm{NS}$ treatments when administered before
PCM, decreased significantly $(P<0.001)$ the serum FasL in the NS/P-treated, H/P-treated and $\mathrm{H} \& \mathrm{NS} / \mathrm{P}$-treated rats when compared to the SHDP-treated rats. In addition, the combined $\mathrm{H} / \mathrm{NS}$ treatment more effectively decreased the serum FasL more than the decrease by either drug alone.

Table 4: The effects of SHDP, NS/P, H/P and H\&NS/P treatments on the serum Fas L in rats

\begin{tabular}{|c|c|}
\hline Animal group & s.Fas L (ng/ml) \\
\hline Control group & $3.28 \pm 0.045$ \\
\hline SHDP-treated group & $25.93 \pm 0.25 \#$ \\
\hline NS/P-treated group & $15.33 \pm 0.11 \# \$$ \\
\hline H/P-treated group & $10.41 \pm 0.11 \# \$$ \\
\hline H\&NS/P-treated group & $3.84 \pm 0.08 \# \$$ \\
\hline
\end{tabular}

- Values are expressed as mean \pm SEM.

\#: Significant in comparison to control group.

\$: Significant in comparison to SHDP-treated group.

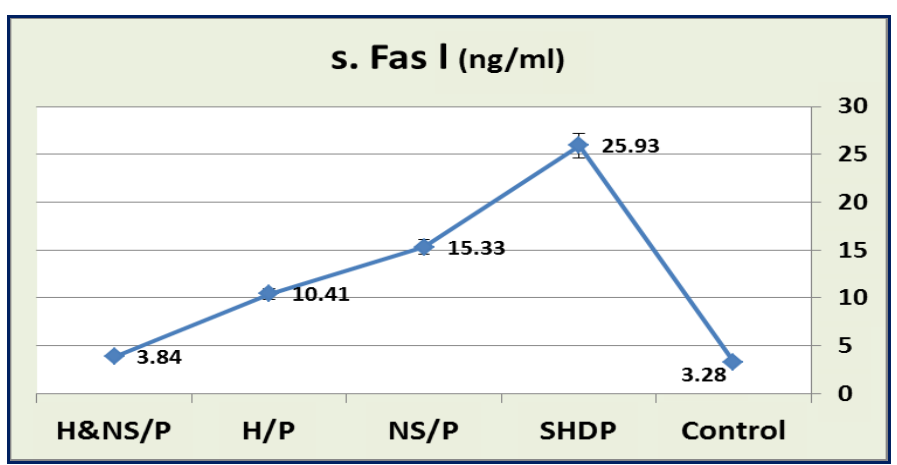

Figure 6: The effects of SHDP, NS/P, H/P and H\&NS/P treatments orally for 4 weeks on serum Fas $L$ in rats 


\section{DISCUSSION}

The studies for treating the toxic liver injury lead us to perform many investigations regarding the hepato- and -nephrotoxicities induced by different drugs and the possible hepato- and nephro-protective effects of therapeutic strategies from the alternative or complementary medicine.

The present work was designed to investigate effects of Sidr honey ( $\mathrm{SH})$ and Nigella sativa oil (NS) on paracetamol (PCM)-induced hepato-renal toxicity in rats. In this study, single high paracetamol (PCM) dose caused significant elevations in the serum ALT and AST liver enzymes, and the serum BUN, creatinine and Fas L, and caused significant reductions in the serum $\mathrm{TAC}$ and liver tissue TAC in SHDP-treated rats. While NS or SH treatment, when given before PCM, prevented the PCM-induced increases in the serum ALT, AST, BUN, creatinine and Fas L, and prevented the PCM-induced decreases in the serum TAC and tissue TAC in SHDP-treated rats. The combined $\mathrm{NS}$ and $\mathrm{H}$ treatment decreased the liver enzymes, improved the renal functions, increased the tissue TAC to nearly the control rats ranges, and, they decreased the serum Fas L more than the decrease done by either drug alone.

At the outset, liver and renal toxicities could be experimentally-examined by administering the compound at increasing doses, in presence of metabolic inducers or inhibitors, with depletion of protective systems, or similarly by coadministering the drug with a known toxic substance ${ }^{[17]}$. First, Lee ${ }^{[18]}$ and Kass ${ }^{[19]}$ stated that cellular organelles with their functions are usually the primary targets of liver toxicity. Likewise, Jaeschke and Bajt ${ }^{[20]}$ explained that reactive metabolite formation, protein alkylation, and antioxidant depletion are the general mechanisms of hepatotoxicity. In the same line, necrotic death occurs following antioxidant depletion and oxidation of intracellular proteins, which lead to increased mitochondrial membrane permeability, decreased ATP synthesis, inhibition of $\mathrm{Ca}^{2+}$ dependent ATPase and decreased ability to sequester $\mathrm{Ca}^{2+}$ in mitochondria. The main intracellular mechanisms that lead to apoptosis are due to activation of nucleases with energy participation of mitochondria ${ }^{[21]}$. In the same way, Grattagliano et al. ${ }^{[1]}$ reported that intracellularly-generated signaling can activate B-cell/lymphoma 2 (Bcl-2) members which promotes the release of intramembranous proteins, chromatin condensation and DNA fragmentation through formation of pores in the outer mitochondrial membrane. Reactive oxygen species (ROS) and peroxynitrite formation, triggering decreased membrane permeability and membrane potential with decreased production of energy are the causative mechanisms for mitochondrial dysfunction.

The deleterious effects of paracetamol on liver and kidney in the present study are in accordance with many authors who reported that paracetamol is predominantly metabolized by conjugation. Only a small amount is metabolized by CYP2E1 to its toxic metabolite NAPQI which is detoxified through binding with GSH [4]. If the total amount of paracetamol reaching the liver exceeds 12-15 g, the conjugating capacity of the liver is exceeded and unfortunately, the remaining unbound NAPQI covalently binds to cellular and mitochondrial proteins, leading to necrotic cell death. Thus, in the presence of CYP2E1 hypertrophy and/or decreased GSH availability (for examples as during malnutrition, chronic alcoholism, and prolonged intake of barbiturates), NAPQI formation is increased even at therapeutic doses, to overwhelm the stores of GSH, and then it may result in severe liver damage ${ }^{[1]}$.

Furthermore, Naguib et al. ${ }^{[3]}$ reported that acetaminophen-induced toxicity is the predominant cause of liver and kidney failure. In humans and rodents, the toxicity starts with the reactive metabolite that binds to proteins, leading to dysfunction of the mitochondria and DNA fragmentation in the nucleus resulting in death of the cell. In addition, Knight et al. ${ }^{[22]}$ clarified that the necrotic process starts with disturbed $\mathrm{Ca}^{2+}$ homeostasis with increased cytosolic $\mathrm{Ca}^{2+}$ levels, oxidative changes in mitochondria and accumulation of oxidized GSH and peroxynitrite. Then induction of membrane permeability, with drop of mitochondrial membrane potential, no synthesis of ATP, and release of mitochondrial proteins, cytochrome $\mathrm{C}$ and endonucleases will happened. Also as showed by Watkins and 
Seeff ${ }^{[23]}$, the deficiency of ATP prevents caspase activation but induces DNA damage, and activates intracellular proteases that lead to liver cell membrane rupture and necrosis. Grattagliano et al. ${ }^{[1]}$ referred the liver cell death and failure observed after paracetamol poisoning to these intracellular events.

It might be argued that the intrinsic properties of the drug, its dose, its metabolites and the local $\mathrm{O}_{2}$ supply are the factors which detect the cellular and intracellular targets. These targets of drug-induced hepatocellular injury include non-parenchymal hepatic cells, mitochondria, and nuclear receptors. Besides, the release of inflammatory mediators and reactive oxygen species (ROS) may be due to activation of Kupffer cells. Also, administration of TNF- $\alpha$ antagonists or inhibition of macrophage activation protects liver cells against paracetamol toxicity [1]. Correspondingly, Kaplowitz ${ }^{[17]}$ and Jaeschke and Bajt [20] found that the drug-induced hepatotoxicity is dose-dependent. Apoptosis and necrosis initially may follow common metabolic pathways. Apoptosis occurs when hepatocyte injury affects the maintenance of cell functions. Necrosis generally begins at the cytoplasm and involves mitochondria.

Hence, drug-induced toxicity results mainly from the reactive metabolite formation, then depletion of GSH and alkylation of proteins with mitochondrial dysfunction. Also, the essential steps in hepatocyte death are opening of pores in the outer mitochondrial membrane, release of proteins and cytochrome $\mathrm{C}$, and intracellular imbalance of $\mathrm{Ca}^{2+}$ homeostasis, and accumulation of $\mathrm{Na}^{+}{ }^{[20]}$. Therefore, detoxification of ROS and maintenance of membrane protein sulfhydryls, including the ATP synthase and the $\mathrm{Ca}^{2+}$-dependent ATPase depends mainly, as confirmed by Lauterburg ${ }^{[4]}$, on the maintenance of mitochondrial GSH pool.

Thus from this concept, our results are in accordance with the reports of many authors [1,17] who found that the drug-induced hepatotoxicity is dose-dependent. The hepatocytes and other cells in the liver with the cellular organelles and their functions are the primary targets of hepatotoxicity, and necrosis is the mechanisms of drug-induced liver injury [19].
In another perspective, Ahmad et al. ${ }^{[9]}$ stated that the N. sativa seeds and their oil are used in the treatment of various diseases. So it is recommended for use on regular basis in Tibbe-Nabwi (Prophetic Medicine) ${ }^{[24]}$. Indeed, Goreja $\left.{ }^{[25}\right]$ explained that N. sativa was showed to possess wide range of activities as gastroprotective, hepatoprotective, antidiabetic, anticancer, immunomodulatory, analgesic, antimicrobial, analgesics and antiinflammatory, bronchodilator, nephroprotective and antioxidant properties. Likewise, as stated by Abel-Salam ${ }^{[8]}$ and Aggarwal and Kunnumakkara ${ }^{[26]}$, N. sativa seeds pharmacologically showed to be used widely in the treatment of various diseases like bronchitis, asthma, diarrhea, and rheumatism and skin disorders. It is also used as liver tonic, diuretic, digestive, appetite stimulant, and to support immune system. Furthermore, Khazdair ${ }^{[27]}$ showed that N. sativa has been widely used in treatment of various CNS disorders such as Alzheimer disease, epilepsy and neurotoxicity. Ahmad et al. ${ }^{[9]}$ referred most of its therapeutic properties to thymoquinone (TQ) which is the major active ingredient of the essential oil. TQ, also the methanol extracts of the shoots roots and seeds inhibited the oxidative stress and exhibited antioxidant activity as evidenced by normalizing glutathione (GSH), catalase $(\mathrm{CAT}), \mathrm{SOD}$ and $\mathrm{NO}^{[28-30]}$. Also, in agreement with our study, Zafeer et al. ${ }^{[31]}$ reported that $\mathrm{N}$. sativa treatment protects the liver in rat against hepatic ischemia reperfusion injury through improving the serum AST, ALT and lactate dehydrogenase (LDH) levels, total oxidative status (TOS), and oxidative stress index (OSI). In addition, Saleem et al. [32] showed that TQ has a protective role on cadmium-induced hepatotoxicity and induces modulatory effect on the antioxidant defense system. Moreover, Ahmad et al. ${ }^{[9]}$ found that both vitamin $\mathrm{C}$ and $\mathrm{N}$. sativa oil produced nephro-protective effect as evidenced from lowering the values of serum creatinine, blood urea nitrogen (BUN), and increasing the antioxidant activity as indicators of gentamicinassociated nephrotoxicity in rabbits, and these two antioxidants combination proved to have synergistic nephroprotective effect. 
Furthermore, Abul-Nasr et al. ${ }^{[33]}$ revealed that $\mathrm{N}$. sativa oil, via reducing serum urea and creatinine levels and increasing TAC levels in kidney tissue and blood, protected against methotrexate-induced nephrotoxicity, and also against renal ischemia-perfusion injury in rat kidneys. Also, oral treatment of N. sativa oil by different doses, in gentamicin (GM)-induced nephrotoxicity in rats, ameliorated the biochemical and histological indicators of GMinduced kidney toxicity; increased plasma total antioxidant status (TAS) and reduced renal cortex GSH concentrations. Hence, as reported by Yildiz et al. ${ }^{[34]}$, in rats, N. sativa oil prevents GM-induced acute nephro-toxicity. TQ stimulated the resistance to oxidative stress. Kim et al. ${ }^{[35]}$ stated that TQ elevated the lowering of mitochondrial transmembrane potential $(\Delta \psi \mathrm{M})$ and attenuated the elevated cytosolic $\mathrm{Ca}^{2+}$ caused by drug toxicity and activated the release of mitochondrial cytochrome-c, increased the expression of Bax and decreased the expression of an antiapoptotic protein (Bcl-2). Cherian et al. ${ }^{[36]}$ and Peng et al. ${ }^{[37]}$ added that TQ stabilizes mitochondrial membrane potential and inhibits apoptotic cascade by decreasing DNA damage. Indeed, it has been reported that TQ exhibits antioxidant, anti-inflammatory and anticancer activities (mediated via peroxisome proliferator-activated receptor gamma, p53dependent and p53-independent pathways), against many types of malignancy, with minimal toxicity in normal cells ${ }^{[38-41]}$. In addition, it has been mentioned that the pharmacological effects of N. Sativa are referred to its strong antioxidant effect which opposes the mitochondrial dysfunction and oxidative stresses associated with drug overdose, and also to antagonizing the free radical-generating agents by reducing reactive oxygen species (ROS), and maintaining the mitochondrial integrity ${ }^{[42-44]}$.

In another perspective, Alvarez-Suarez et al. [45] reported that Aasal, the Arabic name for honey, is a naturally sweet product produced by honeybees from the nectar of blossoms or from the exudates of trees and plants giving the nectar honey. Again, it is a natural, unprocessed and easily digested food and has been shown to have many nutritional and biological effects which include antibacterial, antioxidant, antiviral, antiparasitic, antiinflammatory, anticancer, and immunosuppressive activities. Its antioxidant effects, as confirmed by Jaganathan et al. ${ }^{[46]}$, may be the key in understanding its preventive effect on paracetamol induced hepato-renal toxicity. In the same way it is used for the treatment of burns, faster healing of wound, asthma, and gastrointestinal, skin and eye diseases. Honey is considered to be the first in the line to treat jaundice in traditional medicine of different countries ${ }^{[47]}$. Besides, Chow ${ }^{[48]}$ explained the beneficial composition of honey; it is composed primarily of fructose and glucose but also contains fructooligosaccharides and many amino acids, vitamins, minerals, flavonoids phenolic acids, ascorbic acid, tocopherols, catalase (CAT), superoxide dismutase (SOD), reduced glutathione (GSH), Millard reaction products, peptides and enzymes. Hence, in accordance to our study as mentioned by Ahmad et al. ${ }^{[49]}$, honey has been shown to prevent the reactive oxygen species (ROS)-induced oxidation of low-density lipoprotein (LDL). Also, Erejuwa et al. ${ }^{[50]}$ reported that honey regulates cell cycle hence it can oppose the toxic effect of drug on cell mitochondria and stops the cascade of depletion of GSH pool in hepatic and renal cell mitochondria.

\section{CONCLUSIONS}

The current study indicated that single high paracetamol dose caused a liver toxicity; elevating the serum ALT and AST enzymes, and a kidney toxicity; elevating the serum BUN and creatinine and Fas L, with reductions in the serum and tissue total antioxidant capacity (TAC). Also, this study confirmed that combination of $\mathrm{N}$ sativa oil and Sidr honey protect against these hepatic and renal tissues changes via through their strong antioxidant effects opposing the oxidative damages accompanying paracetamol-induced hepatonephrotoxicity in rats, and thus, could be used as an effective protector against these paracetamol-induced liver and kidney toxicities. Our present issue included the use of sider honey and Nigella sativa oil combination, a strategy directed at factors that cause liver and kidney damage.

More researches in this area are recommended to investigate the therapeutic effects of this 
natural combination and also to evaluate the prophylactic effect of them on other druginduced toxicities in other organs. It is of prior importance to carry out experiments to ensure their prophylactic and therapeutic effects in humans.

\section{ABBREVIATIONS}

PCM: Paracetamol (Acetaminophen), SH: Sidr honey, NS: Nigella sativa oil, SHDP: Single high dose PCM, ALT: alanine transaminase, AST: aspartate transaminase (AST), BUN: Blood urea nitrogen, TAC: Total antioxidative capacity, Fas L: Fas ligand, NAPQI: $N$-acetylp-benzoquinoneimide, GSH: Glutathione, ROS: Reactive oxygen species, Bcl-2: B-cell CLL/lymphoma 2 family members; TNF- $\alpha$ : Tumor necrosis factor alpha; TQ: Thymoquinone, CAT: Catalase; SOD: Superoxide dismutase, TOS: Total oxidative status; OSI: Oxidative stress index, CYP-450: Cytochrome P-450, IL: Interleukin, NF-кB: Nuclear factor-Kb.

\section{ACKNOWLEDGEMENTS}

The authors acknowledge the technician staff of the physiology and clinical pharmacology departments and the animal housing center in the faculties of Medicine, Menoufeya and Zagazig universities, for their valuable assistance.

\section{REFERENCES}

1. Grattagliano I, Bonfrate L, Diogo CV, Wang HH, Wang DQH and Portincasa P. Biochemical mechanisms in drug-induced liver injury: Certainties and doubts. World $\mathrm{J}$ Gastroenterol. 2009;15(39):4865-76.

2. Ghosh A and Sil PC. Anti-oxidative effect of a protein from Cajanus indicus $\mathrm{L}$ against acetaminophen-induced hepato-nephro toxicity. J Biochem Mol Biol. 2007;40(6):1039-49.

3. Naguib YM, Azmy RM, Samaka RM and Salem MF. Pleurotus ostreatus opposes mitochondrial dysfunction and oxidative stress in acetaminophen-induced hepato-renal injury. BMC Complement Altern Med. 2014;14:494504.

4. Lauterburg BH. Analgesics and glutathione. Am J Ther. 2002;9:225-33.

5. Al-Jabri AA. Honey, milk and antibiotics. Afr J Biotechnol. 2005;4:1580-7.

6. Al-Yahya M, Mothana R, Al-Said M, AlDosari M, Al-Musayeib N, Al-Sohaibani M, et al. Attenuation of CCl4-Induced Oxidative Stress and Hepatonephrotoxicity by Saudi Sidr Honey in Rats. Evidence-Based
Complementary and Alternative Medicine. 2013; Article ID 569037, 10 pages.

7. Khaled AAS. Gastroprotective effects of Nigella Sativa oil on the formation of stress gastritis in hypothyroidal rats. Int J Physiol Pathophysiol Pharmacol. 2009;1:143-9.

8. Abel-Salam BK. Immunomodulatory effects of black seeds and garlic on alloxan-induced diabetes in albino rat. Allergol Immunopathol (Madr). 2012;40(6): 336-40.

9. Ahmad A, Husain A, Mujeeb M, Khan SA, Najmi AK, Siddique NA, et al. A review on therapeutic potential of Nigella sativa: A miracle herb. Asian Pac J Trop Biomed. 2013;3(5):337-52.

10. Poulsen HE and Thomsen P. Long term administration of toxic doses of paracetamol (acetaminophen) to rats. Liver. 1988;8:151-6.

11. Pandey G, Srivastava DN and Madhuri S. A standard hepatotoxic model produced by paracetamol in rat. Toxicology international. 2008; 15(1): 69-70.

12. Ebru U, Burak U, Yusuf S, Reyhan B, Arif K, Faruk TH, et al. Cardioprotective effects of Nigella sativa oil on cyclosporine A-induced cardiotoxicity in rats. Basic Clin Pharmacol Toxicol. 2008;103(6):574-80.

13. Haidari F, Omidian K, Rafiei H, Zarei M and Shahi M. Green Tea (Camellia sinensis) Supplementation to Diabetic Rats Improves Serum and Hepatic Oxidative Stress Markers. IJPR. 2013;12:109-14.

14. Meshkibaf MH, Ebrahimi A, Ghodsi R and Ahmadi A. Chronic effects of Lamotrigine on liver function in adult male rats. Indian $\mathrm{J}$ Clin Biochem. 2006; 21(1):161-4.

15. Pan TL, Goto $\mathbf{S}$, Lin YC, Lord R, Chiang KC, Lai CY, et al. The Fas and Fas ligand pathways in liver allograft tolerance. Clin Exp Immunol; 1999; 118(1):180-7.

16. Miller NJ, Rice-Evanc C, Daivies MJ, Gopinathan $\mathbf{V}$ and Milner A. A novel method for measuring antioxidant capacity and its application to monitoring the antioxidant status in premature neonates. Clin. Sci. 1993; 84: 40712.

17. Kaplowitz N. Biochemical and cellular mechanisms of toxic liver injury. Semin Liver Dis. 2002; 22(2): 137-44.

18. Lee WM. Drug-induced hepatotoxicity. N Engl J Med. 2003; 349: 474-85.

19. Kass GE. Mitochondrial involvement in druginduced hepatic injury. Chem Biol Interact. 2006; 163:145-159.

20. Jaeschke $\mathbf{H}$ and Bajt ML. Intracellular signaling mechanisms of acetaminophen- 
induced liver cell death. Toxicol Sci. 2006; 89:31-41.

21. Malhi H, Gores GJ and Lemasters JJ. Apoptosis and necrosis in the liver: a tale of two deaths? Hepatology. 2006; 43: S31-S44.

22. Knight TR, Kurtz A, Bajt ML, Hinson JA and Jaeschke H. Vascular and hepatocellular peroxynitrite formation during acetaminophen toxicity: role of mitochondrial oxidant stress. Toxicol Sci. 2001; 62: 212-20.

23. Watkins PB and Seeff LB. Drug-induced liver injury: summary of a single topic clinical research conference. Hepatology. 2006; 43: 618-31.

24. Al-Bukhari MI. In: Sahih Al-Bukhari, compiled by Imam Muhammad al-Bukhari. The collection of authentic sayings (hadith) of Prophet Mohammad (peace be upon him), division 76 on medicine. 1976; 2nd ed. Ankara: Hilal Yayinlari.

25. Goreja WG. Black seed: nature's miracle remedy. New York, NY 7 Amazing Herbs Press; 2003.

26. Aggarwal BB and Kunnumakkara AB. Molecular Targets and Therapeutic Uses of Spices, Modern Uses for Ancient Medicine. Google Books.2009; p. 259. ISBN 978-9814468-95-4.

27. Khazdair MR. The Protective Effects of Nigella sativa and Its Constituents on Induced Neurotoxicity. Journal of toxicology, 2015; Article ID 841823, 7 pages.

28. El Gendy S, Hessien M, Abdel Salam I, Morad M, EL-Magraby K, Ibrahim HA, et al. Evaluation of the possible antioxidant effects of Soybean and Nigella sativa during experimental hepatocarcinogenesis by nitrosamine precursors. Turkish $\mathrm{J}$ Biochem. 2007; 32(1): 5-11.

29. Umar S, Zargan J, Umar K, Ahmad S, Katiyar CK and Khan HA. Modulation of the oxidative stress and inflammatory cytokine response by thymoquinone in the collagen induced arthritis in Wistar rats. Chem Biol Interact. 2012;197(1): 40-6.

30. Bourgou S, Pichette A, Marzouk B and Legault J. Antioxidant, antiinflammatory, anticancer and antibacterial activities of extracts from Nigella Sativa (Black Cumin) plant parts. J Food Biochem. 2012;36(5): 53946.

31. Zafeer MF, Waseem M, Chaudhary $\mathbf{S}$ and Parvez S. Cadmium-induced hepatotoxicity and its abrogation by thymoquinone. J Biochem Mol Toxicol 2012; 26(5): 199-205.

32. Saleem U, Ahmad B, Rehman K, Mahmood S, Alam $M$ and Erum A. Nephro-protective effect of vitamin $\mathrm{C}$ and Nigella sativa oil on gentamicin associated nephrotoxicity in rabbits. Pak J Pharm Sci. 2012; 25(4):727-30.

33. Abul-Nasr SM, El-Shafey MDM and Osfor MMH. Amelioration by Nigella sativa of methotrexate induced toxicity in male albino rats: a biochemical, haematological and histological study. Scintia Agri Bohemica. 2001;32:123-60.

34. Yildiz F, Coban S, Terzi A, Savas M, Bitiren M, Celik H, Aksoy N. Protective effects of Nigella sativa against ischemia-reperfusion injury of kidneys. Ren Fail. 2010; 32(1): 12631.

35. Kim MY, Zhang T and Kraus WL. Pol(ADPribosyl)ation by PARP-1:PAR-laying NAD in to nuclear signal. Genes Dev. 2005; 19:195167.

36. Cherian PP, Schenker S and Henderson GI. Ethanol-mediated DNA damage and PARP-1 apoptotic responses in cultured fetal cortical neurons. Alcohol Clin Exp Res. 2008; 32:1-9.

37. Peng L, Liu A, Shen Y, Xu HZ, Yang SZ, Ying XZ, et al. Antitumor and antiangiogenesis effects of thymoquinone on osteosarcoma through the NF- $\mathrm{B}$ pathway. Oncol Rep. 2013;29:571-578.

38. Heaton MB, Paiva $M$ and Marsiglio KS. Ethanol influences on Bax translocation, mitochondrial membrane potential, and reactive oxygen species generation are modulated by vitamin $\mathrm{E}$ and brain-derived neurotrophic factor. Alcohol Clin Exp Res. 2011; 6:1-12.

39. Woo CC, Loo SY, Gee V, Yap CW, Sethi G, Kumar AP, Tan KH. Anticancer activity of thymoquinone in breast cancer cells: possible involvement of PPAR- $\gamma$ pathway. Biochem Pharmacol. 2011;82(5):464-75.

40. Das S, Dey KK, Dey G, Pal I, Majumder A, MaitiChoudhury S, et al. Antineoplastic and Apoptotic Potential of Traditional Medicines Thymoquinone and Diosgenin in Squamous Cell Carcinoma. PloS One 2012;7(10): e46641.

41. Lei X, Lv X, Liu M, Yang Z, Ji M, Guo X, Dong W. Thymoquinone inhibits growth and augments 5-fluorouracil-induced apoptosis in gastric cancer cells both in vitro and in vivo. Biochem Biophysics Res Commun 2012;417(2) 864-8.

42. Martin TM, Benghuzzi $\mathbf{H}$ and Tucci $M$. The effect of conventional and sustained delivery of thymoqinone and levodopa on SH-SY5Y human neuroblastoma cells. Biomed Sci Instrum. 2006; 42:332-7.

43. Kanter M. Nigella sativa and derived thymoquinone prevents hippocampal neurodegeneration after chronic toluene 
exposure in rats. Neurochem Res. 2008; 33:579-88.

44. Mousavi SH, Tayarani-Najaran Z, Asghari $M$ and Sadeghnia HR. Protective effect of nigella sativa extract and thymoquinone on serum/glucose deprivation-induced PC12 cells death. Cell Mol Neurobiol. 2010; 30:591-8

45. Alvarez-Suarez JM, Tulipani S, Romandini S, Bertoli E, and M. Battino M. Contribution of honey in nutrition and human health: a review. Mediterranean Journal of Nutrition and Metabolism 2010; 3(1): 15-23.

46. Jaganathan SK, Balaji A, Vellayappan MV, Asokan MK, Subramanian AP, John AA, et al. Anti-Cancer Agents in Medicinal Chemistry. Bentham Science J. 2015; 15(1):48-56.

47. Andritoiu CV, Ochiuz L, Vasile Andritoiu V and Popa M. Effect of Apitherapy
Formulations against Carbon TetrachlorideInduced Toxicity in Wistar Rats after Three Weeks of Treatment. Molecules 2014;19:13374-91.

48. Chow J. Probiotics and prebiotics: a brief overview. J Ren Nutr. 2002;12:76-86.

49. Ahmad A, Khan RA and Mesaik MA. Antiinflammatory effect of natural honey on bovine thrombin-induced oxidative burst in phagocytes. Phytother Res. 2009;23:801-8.

50. Erejuwa OO, Sulaiman SA and Wahab MS. Effects of honey and its mechanisms of action on the development and progression of cancer. Molecules 2014;19(2):2497-522. 